\title{
Hybrid sliding PID controller for torsional vibrations mitigation in rotary drilling systems
}

\author{
Chafiaa Mendil $^{1}$, Madjid Kidouche ${ }^{2}$, Mohamed Zinelabidine Doghmane ${ }^{3}$ \\ ${ }^{1,2,3}$ Laboratory of Applied Automatic, Department of automation and electrification of industrial process, Faculty of \\ Hydrocarbons and Chemsitry, M'hamed Bougara Universitiy of Boumerdes, Algeria \\ ${ }^{3}$ Exploration and Production Division, SONATRACH, Hassi Messaoud, Algeria
}

\section{Article Info}

Article history:

Received Oct 30, 2020

Revised Jan 21, 2021

Accepted Feb 3, 2021

\section{Keywords:}

Hybrid sliding PID controller

Rock-bit interaction

Rotary drilling system

Stick-slip phenomenon

Torsional vibrations

\begin{abstract}
During the drilling process, the drilling system devices can be exposed to several types of phenomena incited by lateral, axial, and torsional vibrations. The latter can lead to severe damages if they are not efficiently controlled and quickly mitigated. This research work is focused on the torsional vibrations, which are stimulated by the nonlinear dynamical interaction between the geological rocks and the drill bit. Wherein, a model with three degrees of freedom was designed to demonstrate the severity of the stick-slip phenomenon as consequence of torsional vibrations. The main objective of this study was to design a robust controller based on hybridizing a conventional PID controller with sliding mode approach in order to mitigate rapidly the torsional vibrations. Moreover, a comparative study between PI, PID and sliding mode controllers allowed us to emphasize the effectiveness of the new hybrid controller and improve the drilling system performances. Furthermore, the chattering phenomenon in the sliding surface was overcome by using the saturation function rather than the sign function. The obtained results proved the usefulness of the proposed controller in suppressing the stick-slip phenomenon for smart industrial drilling systems.
\end{abstract}

This is an open access article under the CC BY-SA license.

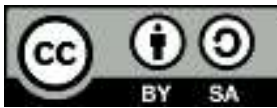

Corresponding Author:

Chafiaa Mendil

Department of Automation and Electrification of Industrial Process

Faculty of Hydrocarbons and Chemistry

M'hamed Bougara University of Boumerdes

Avenu L'independence 35000, Boumerdes, Algeria

Email: c.mendil@univ-boumerdes.dz

\section{INTRODUCTION}

In the last few years, many researches about the vibrations in rotary drilling systems have been conducted in the literature, wherein, axial, lateral, and torsional vibrations have been discussed with many details [1-3]. In this research work, the torsional vibrations control and mitigation is considered because it is the stimulator of the Stick-slip phenomenon, which by its turn can be one of the main generators of the axial and lateral vibrations. The appearance of this phenomenon can lead to blocking the drilling tool during the stick phase, and damage other devices during the slip phase due to the cumulated energy release [4]. Many control systems have been proposed in the last two decades to reduce the severity of the torsional vibrations in rotary drilling systems [5]. Navarro and Castro have proposed the use of PI and sliding mode controllers in [6], the latter can only maintain the desired rotational speeds but with some oscillations. On the other hand, the proposed PI controller minimizes oscillations but it takes considerable time that expands the duration of the stick phase. Amadou has proposed in [7] three control laws by sliding mode, PID and linearization, where 
acceptable performance has been obtained; the comparative study between the controllers has also been conducted. However, the dynamic of the studied model did not highlight the stick-slip phenomenon dynamic. Furthermore, Lui in [8] has used three sliding mode controllers to suppress the Stick-Slip oscillations; this study is an extension of contribution proposed by Navarro in [6]. Even though the design of three sliding mode controllers, the stick phase duration is still considerable because of activation delays in the control system. In last few years, the sliding-mode control method has been used to experimentally and numerically suppress stick-slip vibrations during drilling [9], the controller succeeded in eliminating the stick-slip oscillation but only for appropriately designed test bench. Though, when comparing the latest published studies, they have generally assumed that the input of the system is the torque delivered by the Top drive, hence, all the torques that exist between the top drive and the first element were neglected, so the speed of the first element is the same as the top drive speed. This hypothesis is the reason why the stick-slip phenomenon is not well observed since the torsional vibrations are not severe, in another way, the numerical model is not appropriately reliable, and does not precisely provide the accurate speed of the tool and that of the top drive. This limitation causes many problems during applying the functions of the drilling device (pumping and rotation). The disadvantage of these studies is that the used system model is limited to low oscillatory vibrations; therefore, in case of high frequency oscillating mode of the stick-slip vibrations, the performance of the previously developed controllers will be questionable. From other side, the dynamic mode is directly related to the rock-bit interaction term and the number of freedom degrees of the considered system, thus, these factors will make it more difficult to obtain good performances of rotary drilling system under severe torsional vibrations in its high frequency stick-slip mode. The latest proposed solutions, unfortunately, were limited to average performances and did not allow obtaining good performances. For that reasons, in this study the proposed model took the Top drive speed as an input, without neglecting the resisting torque between the top drive and the first element. Moreover, to eliminate the high vibrations, we proposed the design of a robust controller that mitigates the torsional vibrations (in its severe mode) in an optimal time so that protection of drilling equipment from hazards and damages can be efficiently guaranteed.

To address the above limitations, the main objective of this research work is to minimize the torsional vibrations of the drill string by improving the efficiency of the proposed controller, and consequently guarantee the proper functioning of the drilling equipment during drilling for the smart industrial rotary drilling systems. Wherein, the top drive rotational velocity is considered as an input of the system, three rock-bit interaction models have been analyzed (simplified model, generalized model, and Stribeck) [10], and their effects on the model dynamic and the stick-slip phenomenon severity have been carefully discussed. Therefore, the generalized model of rock-bit interaction dynamic was used in the model of the system in order to design three controllers: classic PID controller [11], sliding mode controller [12], and hybrid sliding PID controller [13], they were designed to mitigate the stick-slip vibrations. The main advantages of the latter controller is its ability to eliminate the chattering phenomenon, the controllers' performances were principally evaluated based on their response time because the dynamic of the vibrations is very fast in comparison to manual human intervention in the industrial rotary drilling systems [14]. Besides, the robustness of the hybrid controller was checked accordingly to parametric variations and monitoring, which guarantees our controller efficiency even with structured disturbances. Another advantage is that these controllers have not been previously applied for the used model. In order to attract readers to the proposed contributions in this study, we gave in section two a description of typical rotary drilling system [15].

\section{ROTARY DRILLING SYSTEM}

Drilling process is a technique of digging a hole in the ground to extract products like oil, and gas. Each technique is chosen based on specific drilling operations, which depend on the nature of the geological formations (especially rock hardness) and the mechanical strength of the soil (well walls stability and behavior of drilling mud). Among these techniques, the rotary drilling is distinguished; it exists since 1920 when it was developed mainly for light devices (works power of $650 \mathrm{Hp}$ ) and used in unconsolidated sedimentary soils. This drilling system has the advantage of good control of drilling parameters (weight on bit, rotational velocity, mud quality and its injection rate) [16]. The drilling rig is composed of several elements, all of them are important and each of them has a specific role so that the safety is ensured by blow out preventers (BOP), the pumping process is guaranteed by the mud pump, the rotation is ensured by the top drive and the rotary table, and the production of alternative energy is provided by diesel motors. In addition to that, the drill string consists of drill pipes, drill collars, they ensure the proper functioning of the tool during its rotation, without forgetting the most important component of drilling which is the tool, it can be either as toothed wheels or diamond tool (natural or synthetic diamonds: PDC and TSP) [17]. 


\section{TORSIONAL VIBRATIONS}

Figure 1 shows the torsional vibration in stick-slip mode generated by parametric variations due geological formation requirements and weight on bit (WOB) monitoring. Stick-slip phenomenon is the severe status of the torsional vibrations; it can lead to damaging the drill bit, the tool string, or even the top drive if it last for a considerable period without control. In best scenario, it increases the non productive time (NPT) up to $50 \%$ of the total drilling time. The highly nonlinear rock-bit interaction dynamic is the main cause of such type of vibrations [18], for which the bit is characterized by unstable rotational speed that varies aggressively as function of sudden changes in rock geomechanical properties. Thus, the behavior of rotary drilling system during the oscillations cannot be completely predictable. For that reason, the design of friction model was not an easy task [19], where, it was necessary to introduce a large number of parameters to describe the physics of friction phenomena. Among the studied friction models, the general model has demonstrated its high representability to stick-slip phenomenon in its high frequency mode and the severe torsional vibrations.

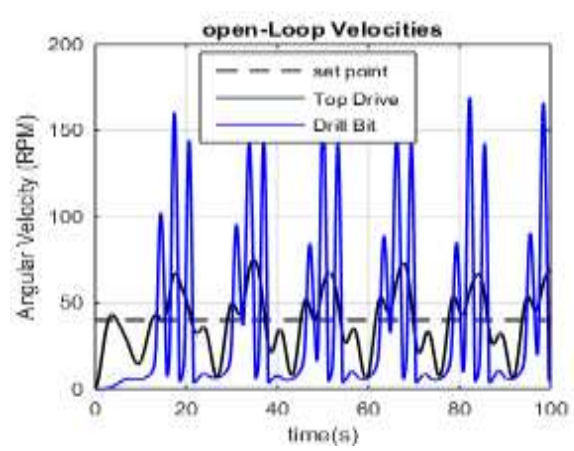

(a)

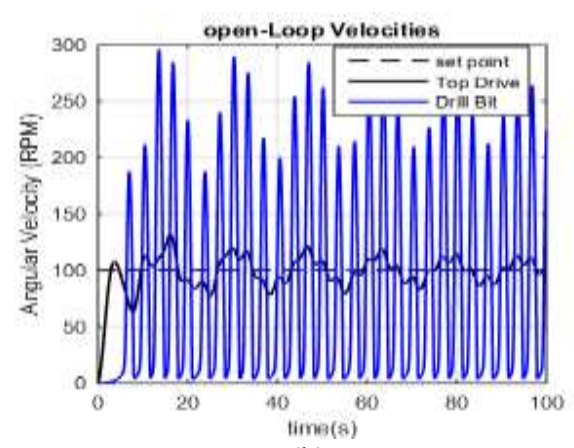

(b)

Figure 1. Stick-slip vibration simulation with: (a) Input velocity of $40 \mathrm{rpm}$ and $\mathrm{Wob}=120 \mathrm{~N}$ (b) Input velocity of $100 \mathrm{rpm}$ and $\mathrm{Wob}=200 \mathrm{~N}$

\section{DRILL STRING MODEL}

The analysis of torsional vibrations appearing in the drillstring can be done through a proxy model of a torsion pendulum (Mass-spring-damper) because it is the most answered one for such type of studies [20]. It was firstly proposed by National Oilwell Varco (NOV) company [21]. Figure 2(a, b) show the complete drilling rig and its schematic diagram, while Figure 2(c) demonstrates its equivalent proxy system. It has three degrees of freedom where the upper disc represents the rotary table, the middle disc is considered as the tool string, and the lower disc represents the drill bit. The description of the model parameters was summarized in Table 1.

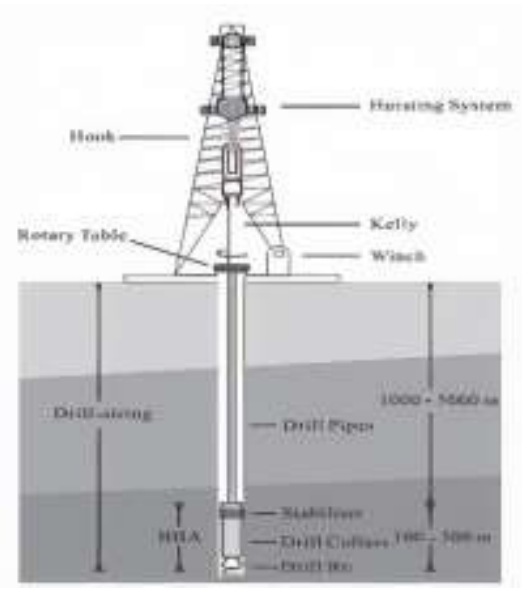

(a)

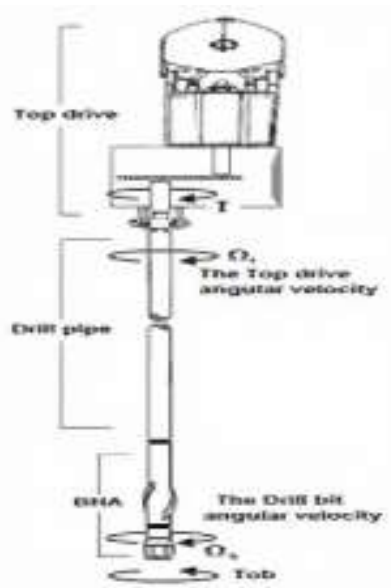

(b)

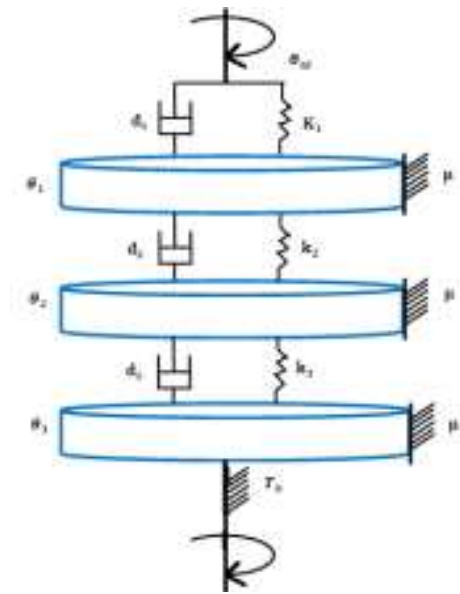

(c)

Figure 2. Rotary drilling system: (a) Complete Drilling rig [8], (b) Its Schematic diagram [19], (c) Equivalent Proxy model with three elements 
The three-element proxy model of rotary drilling system is described by (1):

$$
\left\{\begin{array}{c}
\ddot{\theta}_{1}=\frac{1}{j_{1}}\left(d_{1}\left(\dot{\theta}_{t d}-\dot{\theta}_{1}\right)-k_{1}\left(\theta_{t d}-\theta_{1}\right)-d_{2}\left(\dot{\theta}_{1}-\dot{\theta}_{2}\right)-k_{2}\left(\theta_{1}-\theta_{2}\right)-\mu \dot{\theta}_{1}\right) \\
\ddot{\theta}_{2}=\frac{1}{j_{2}}\left(d_{2}\left(\dot{\theta}_{1}-\dot{\theta}_{2}\right)+k_{2}\left(\theta_{1}-\theta_{2}\right)-d_{3}\left(\dot{\theta}_{2}-\dot{\theta}_{3}\right)-k_{3}\left(\theta_{2}-\theta_{3}\right)-\mu \dot{\theta}_{2}\right) \\
\ddot{\theta}_{3}=\frac{1}{j_{3}}\left(d_{3}\left(\dot{\theta}_{2}-\dot{\theta}_{3}\right)+k_{3}\left(\theta_{2}-\theta_{3}\right)-\mu \dot{\theta}_{3}-T_{b}\right)
\end{array}\right.
$$

Table 1. Parameters description for the designed rotary drilling model

\begin{tabular}{clc}
\hline Parameter & Description & Unit \\
\hline$\theta_{t d}$ & The top drive angular displacement & [rad] \\
$\theta_{i=1,2,3}$ & The angular displacements of the rope section $i$ & [rad] \\
$k_{i=1,2,3}$ & Torsional stiffness coefficient of the rope section $i$ & [N.m/rad] \\
$d_{i=1,2,3}$ & Internal damping coefficient of the rope section i & [N.m.S $/ \mathrm{rad}]$ \\
$\mu$ & Wall friction coefficient & [N.m] \\
$j_{i=1,2,3}$ & The inertia of the rope section i & {$\left[\mathrm{kg} \cdot \mathrm{m}^{2}\right]$} \\
\hline
\end{tabular}

To use the standard notation for states and inputs in (1), the following variable changes were applied: $\dot{\theta}_{1} \triangleq$ $x_{1}, \dot{\theta}_{2} \triangleq x_{2} \dot{\theta}_{3} \triangleq x_{3}, \theta_{t d}-\theta_{1} \triangleq x_{4}, \theta_{1}-\theta_{2} \triangleq x_{5}, \theta_{2}-\theta_{3} \triangleq x_{6}, \dot{\theta}_{t d}=\mathrm{u}$.

The state equations of the system were then rewritten in the form given by (2).

$$
\left\{\begin{array}{l}
\dot{x}_{1}=A_{1} x_{1}+A_{2} x_{2}+A_{3} x_{4}+A_{4} x_{5}+A_{5} u \\
\dot{x}_{2}=B_{1} x_{1}+B_{2} x_{2}+B_{3} x_{3}+B_{4} x_{5}+B_{5} x_{6} \\
\dot{x}_{3}=C_{1} x_{2}+C_{2} x_{3}+C_{3} x_{6}+C_{4} T_{b} \\
\dot{x}_{4}=\dot{\theta}_{t d}-\dot{\theta}_{1}=u-x_{1} \\
\dot{x}_{5}=\dot{\theta}_{1}-\dot{\theta}_{2}=x_{1}-x_{2} \\
\dot{x}_{6}=\dot{\theta}_{2}-\dot{\theta}_{3}=x_{2}-x_{3}
\end{array}\right.
$$

Where

$$
\left\{\begin{array}{l}
A_{1}=\frac{-d_{1}-d_{2}-\mu}{j_{1}} \\
A_{2}=\frac{d_{2}}{j_{1}} \\
A_{3}=\frac{k_{1}}{j_{1}} \\
A_{4}=\frac{-k_{2}}{j_{1}} \\
A_{5}=\frac{d_{1}}{j_{1}}
\end{array} ;\left\{\begin{array}{l}
B_{1}=\frac{d_{2}}{j_{2}} \\
B_{2}=\frac{-d_{2}-d_{3}-\mu}{j_{2}} \\
B_{3}=\frac{d_{3}}{j_{2}} \\
B_{4}=\frac{k_{2}}{j_{2}} \\
B_{5}=\frac{-k_{3}}{j_{2}}
\end{array} ;\left\{\begin{array}{l}
C_{1}=\frac{d_{3}}{j_{3}} \\
C_{2}=\frac{-d_{3}-\mu}{j_{3}} \\
C_{3}=\frac{k_{3}}{j_{3}} \\
C_{4}=\frac{-1}{j_{3}}
\end{array}\right.\right.\right.
$$

The matrix form was then obtained as given by (4).

$$
\left\{\begin{array}{l}
\dot{x}(t)=A(x(t))+B(x) u(t) \\
Y(t)=C(x(t))
\end{array}\right.
$$

$\mathrm{Y}(\mathrm{t})$ is the measured output variable which is drill bit speed, where $\mathrm{x}(\mathrm{t})=\left[\begin{array}{llllll}x_{1} & x_{2} & x_{3} & x_{4} & x_{5} & x_{6}\end{array}\right]$ is the state vector, with

$$
C(x)=\left[\begin{array}{llllll}
0 & 0 & 1 & 0 & 0 & 0
\end{array}\right], \mathrm{A}(\mathrm{x})=\left[\begin{array}{l}
A_{1} x_{1}+A_{2} x_{2}+A_{3} x_{4}+A_{4} x_{5} \\
B_{1} x_{1}+B_{2} x_{2}+B_{3} x_{3}+B_{4} x_{5}+B_{5} x_{6} \\
C_{1} x_{2}+C_{2} x_{3}+C_{3} x_{6}+C_{4} T_{b} \\
-x_{1} \\
x_{1}-x_{2} \\
x_{2}-x_{3}
\end{array}\right], \mathrm{B}(x)=\left[\begin{array}{c}
A_{5} \\
0 \\
0 \\
1 \\
0 \\
0
\end{array}\right]
$$

Where $T_{b}$ is the torque on the bit, it represents the nonlinearity term, and it is given by (5). 


$$
\mathrm{T}_{\mathrm{b}}=\mathrm{x}_{3}\left(\frac{\mathrm{A}}{\sqrt{\mathrm{x}^{2}{ }_{3}+\Omega^{2}{ }_{0}}}+\frac{\mathrm{B}}{\mathrm{x}^{2}{ }_{3}+\Omega^{2}{ }_{0}}\right)-\mathrm{Dx}_{3}\left(\frac{\mathrm{x}_{3}}{\Omega_{1}}-1\right)
$$

Where $\mathrm{A}=\mu_{n} N r$, and $\mathrm{B}=\mathrm{A} p \Omega_{0}$, the numerical values for the various constants used in the simulation are: $K_{1}=K_{2}=K_{3}=481.29 \mathrm{~N} . \mathrm{m} / \mathrm{rad}, j_{1}=j_{2}=1030.45 \mathrm{Kg} \cdot \mathrm{m}^{2}, j_{3}=223.44, d_{1}=d_{2}=51.38 \mathrm{~N} . \mathrm{m} . \mathrm{s} / \mathrm{rad}$, $d_{3}=39.79 \mathrm{~N} . \mathrm{m} . \mathrm{s} / \mathrm{rad}, \mu=10 \mathrm{~N} . \mathrm{m}, \mathrm{Wob}=120 \mathrm{~N} . \mathrm{m}$, the parameters in (5) are summarized in Table 2.

$\underline{\text { Table 2. Parameters description of Torque on bit term }}$

\begin{tabular}{clc}
\hline Parameter & Description & Value \\
\hline$\mu_{n}$ & Nominal friction coefficient & $40 \mathrm{Nm}$ \\
$\mathrm{N}$ & The force vector & $9.81 \times$ Wob N \\
$\mathrm{R}$ & The contact radius vector & $0.1 \mathrm{~m}$ \\
$\Omega_{0}$ & Chain transition speed & 1 \\
$\Omega_{1}$ & Transition speed for the well & 31.4159 \\
$\mathrm{P}$ & The initial friction parameter & 1.5 \\
$\mathrm{D}$ & The linear damping vector & 0.28 \\
\hline
\end{tabular}

\section{CONTROLERS DESIGN}

\subsection{Sliding mode controller (SMC)}

The SMC is a two-part controller design process; the first part associates with the design of a sliding surface so that the sliding motion satisfies the design specifications dealt with it. The second part focuses on the selection of a control law that will make the switching surface attract the system state. The control problem, which minimizes the problem of driving the system to its surface and then ensuring that it stays on this surface all the time, is based on Lyapunov approach [22]. The sliding mode controller was designed through the following steps:

Step 1. The choice of the sliding surface; it is defined according to the order of the system as given in (6).

$$
\mathrm{s}(\mathrm{x})=\left(\frac{d}{d t}+\lambda\right)^{n-1} \mathrm{e}(\mathrm{x})
$$

With $e(x)=x_{d}-x, n$ is the relative order of the system compared to the output $y(t), x_{d}$ is the desired set point, and $e$ is the error.

Step 2. The condition of existence and the convergence of the slip regime: these criteria allow the states of the system to converge towards the sliding surface, and oblige them to remain in the vicinity of the sliding surface [23]. The condition is given by (7); it only guarantees an asymptotic convergence towards the sliding surface. However, to obtain a convergence in finite time, condition (8) should be verified.

$$
\begin{aligned}
& \dot{S} . s<0 \\
& \dot{S} . s<-k|s|
\end{aligned}
$$

With: $\mathrm{k}>0$

The conditions in (7) and (8) are derived from Lyapunov methodology where a positive scalar function $v(x)>0$ is chosen as:

$$
V(s)=\frac{1}{2} s^{2}
$$

Its derivative is calculated and investigated to be negative or at least semi-negative.

$$
\dot{V}(\mathrm{x})=\mathrm{s}(\mathrm{x}) \cdot \dot{\mathrm{s}}(\mathrm{x})
$$

Step 3. Determination of the control law: this law is broken down into two equations; the first is the equivalent control law $u_{e q}$ which is given in (11), Which represents the continuous part of the input, as obtained by the derivation of the sliding surface (s), and canceling all the terms which hinder the stability of the system, Physically, it can be interpreted as the average value of the real command [24]. The second equation is the discontinuous law $u_{d}$, which is added for the purpose of eliminating the chattering phenomenon [25]. There are several functions that can be used to eliminate this phenomenon, in this paper 
we choose to use (12), (13), and (16) have been considered as discontinuous control law of the sliding controller for the chosen surface expressed in (15). The sign function given in (12) has been replaced by a saturation function (13) because it has less discontinuity so that the chattering phenomenon can be avoided.

$$
\begin{gathered}
U=u_{e q}+u_{d} \\
u_{d 1}=k \cdot \operatorname{sign}(s(x)) \\
u_{d 2}=k \operatorname{sat}(s(x)
\end{gathered}
$$

With

$$
\operatorname{sat}(\mathrm{s})= \begin{cases}\frac{s}{\varphi} & \text { si }\left|\frac{s}{\varphi}\right| \leq 1 \\ \operatorname{sgn}\left(\frac{s}{\varphi}\right) & \text { si }\left|\frac{s}{\varphi}\right| \geq 1\end{cases}
$$

With: $\varphi$ is the transition band of the sliding surface Then, the sliding surface became

$$
\mathrm{s}=\left(x_{1}-Q_{r e f}\right)+\lambda\left[\int_{0}^{t} x_{1}(\tau)-Q_{\text {ref }} d \tau+\lambda \int_{0}^{t} x_{1}(\tau)-x_{3}(\tau) d \tau\right]
$$

And the sliding control law was obtained as given in (16).

$$
\mathrm{U}_{\mathrm{sli}}=\frac{1}{A_{5}}\left[-A_{1} x_{1}-A_{2} x_{2}-A_{3} x_{4}-A_{4} x_{5}-\lambda\left(x_{1}-Q_{r e f}\right)-\lambda\left(x_{1}-x_{3}\right)-u_{d}\right]
$$

With: $\mathrm{k}, \lambda>0$

\subsection{PID controller}

PID (proportional, integral, derivative) controllers are classic controllers [26]; they have been widely used in the industry for several systems and applications [27, 28]. The control laws for PI and PID regulators are given by (17) and (18) respectively.

$$
\begin{aligned}
& \mathrm{U}_{\mathrm{PI}}=k_{p}\left(1+\frac{1}{T_{i} s}\right) \\
& \mathrm{U}_{\mathrm{PID}}=-k_{p}\left(1+\frac{1}{T_{i} s}+T_{d} \cdot s\right)
\end{aligned}
$$

With: $k_{p}$ is a proportional gain, $T_{i}$ is an integral time constant, and $T_{d}$ is a derivative time constant.

\subsection{Hybrid PID sliding mode controller}

The hybrid controller consists of making a combination between two control laws [29]; the first is that of the classic PID (or PI) controller which compensates for the drilling non-linearity caused by the stickslip vibrations [30], it also prevents the tool from sticking. While, the second controller with its sliding mode improves the robustness of the proposed method and ensures the desired rate of penetration, the mathematical formula for PID (PI) sliding mode controller are described by (19) and (20) respectively.

$$
\begin{aligned}
& U_{\text {sli_pi }}=U_{\text {sli }}+U_{P I} \\
& U_{\text {sli_pid }}=U_{\text {sli }}-U_{\text {PID }}
\end{aligned}
$$

Where: $\mathrm{U}_{\mathrm{PI}}$ is the PI controller law in (17), $\mathrm{U}_{\mathrm{PID}}$ is the PID controller law in (18), and $\mathrm{U}_{\text {sli }}$ is the sliding mode control law in (16). 


\subsection{Controllers' robustness}

To investigate the controller robustness due to parametric variations, (21) was proposed.

$$
\mathrm{U}_{\mathrm{sli}}=\frac{1}{A_{5}}\left[-\Delta_{1} A_{1} x_{1}-\Delta_{2} A_{2} x_{2}-\Delta_{3} A_{3} x_{4}-\Delta_{4} A_{4} x_{5}-\lambda\left(x_{1}-Q_{r e f}\right)-\lambda\left(x_{1}-x_{3}\right)-u_{d}\right]
$$

Where: $\Delta_{i}$ are positive constants which adjust the model parameters. Based on the obtained responses, the robustness can be then quantified [31,32], with $0<\Delta_{i}<1$.

\section{RESULTS AND DISCUSSION}

In order to study the open-loop model and to prove that the studied system is subjected to strong torsional vibrations in its high-frequency stick-slip mode, and to monitor the efficiency of this closed-loop model (sliding mode controller (SMC), PID controller and hybrid PID sliding mode controller), the MATLAB R2015 environment has been used, which enabled the implementation of the model shown in (2) and displays response graphs. Based on the results, we were able to make an evaluation of the performances and interpretations of the responses' characteristics (Overshoot, Stabilization time, Static difference) and to assess the effectiveness of these controllers applied for the rotary drilling model.

\subsection{Open loop responses}

Figure 3(a) shows the top drive angular velocity in black and the bit angular velocity in blue for open loop response of the system. As noted in previous section, the general rock-bit interaction term has been used since it represents the stick-slip dynamic with high fidelity. By setting the $W o b=120 \mathrm{~N}$. $\mathrm{m}$ for an input velocity of $100 \mathrm{rpm}$, the bit speed oscillates, but, the top drive oscillations are less than the bit oscillations due vibrations absorption from the bottom hole up to surface. It is also noticeable that the maximum bit velocity exceeded the double of the top drive velocity at the slip phase, and then decreased to near zero at the stick phase repetitively. Moreover, to analyze these phases, Figure 3(b) was shown to demonstrate the torque on bit variations during the oscillations, where the maximum torque was $180 \mathrm{~N} . \mathrm{m}$ which is obtained at the end of each stick phase while the minim value was $100 \mathrm{~N}$. $\mathrm{m}$ which is obtained at the end of each slip phase. Thus, the torque variation is a direct indicator of the torsional vibration severity.

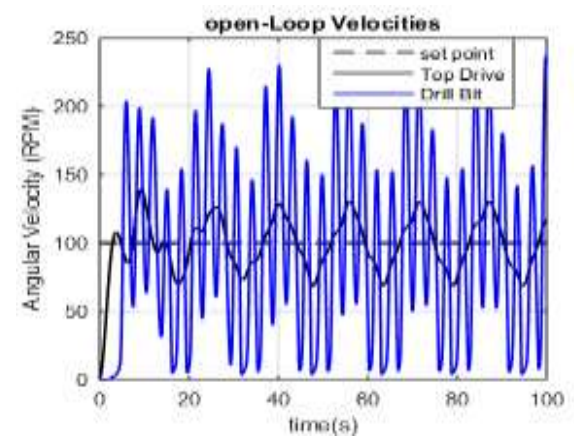

(a)

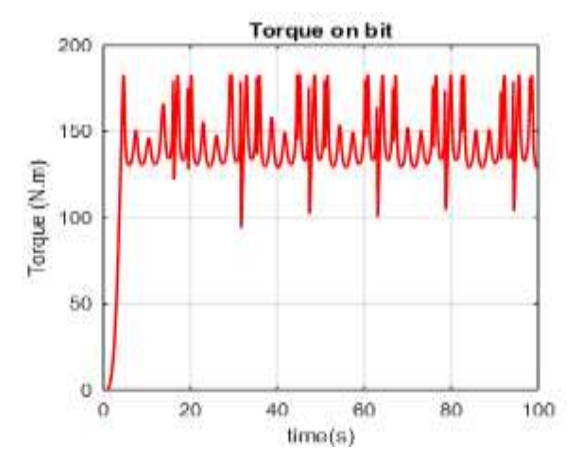

(b)

Figure 3. Open loop responses of rotary drilling system for: (a) The angular velocities, (b) The Torque on bit

\subsection{Sliding mode controller results}

Figure 4(a) shows the top drive and the bit rotational velocities under the designed sliding mode controller [33], it was noted that the performances of the system has been improved, where the oscillations have been reduced at the bit and removed at the top drive. The responses had stabilized at $t=10 \mathrm{~s}$, without overshoot, therefore without a static difference. These performances really prove the effectiveness and the validity of the designed controller in comparison to time response of controllers in latest studies like results in [8]. Nevertheless, the chattering phenomenon had appeared at the control input as shown in Figure 4(b), it is mainly caused by the discontinuous sign function given by (12). To eliminate the chattering effects [34], other functions were considered too. Figure 5(a) shows the angular velocities of the top drive and that of the drill bit with a sliding mode controller by using saturation function given by (14). By using an equivalent saturation control, the performance of the system remained the same as in Figure 4(a), but the chattering phenomenon has been eliminated as illustrated in Figure 5(b) so that the control system was improved too. 


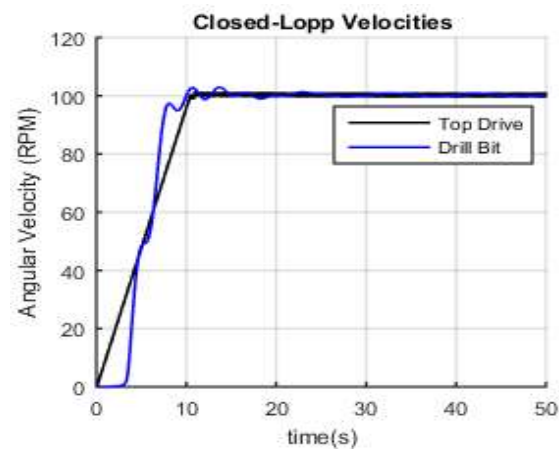

(a)

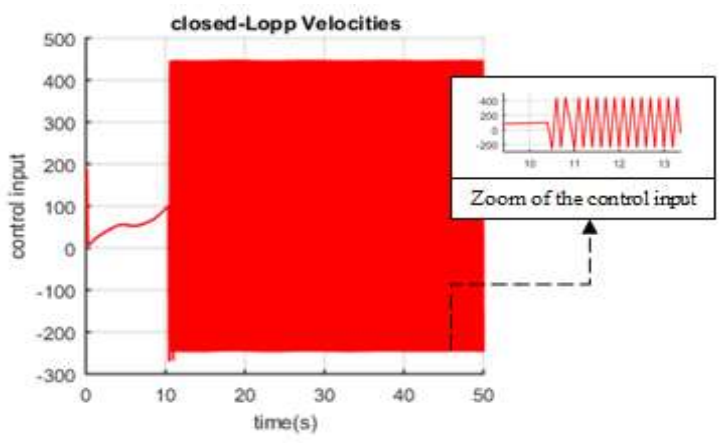

(b)

Figure 4. The sliding mode control step response for: (a) The angular velocities, (b) Control input

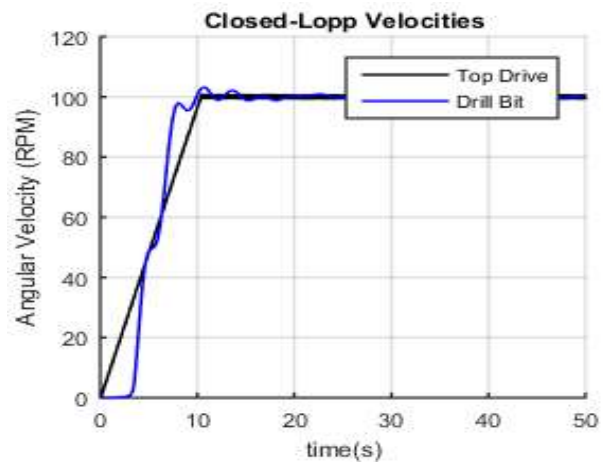

(a)

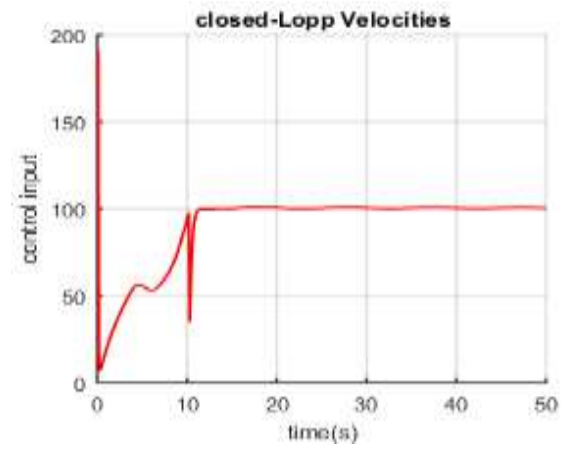

(b)

Figure 5. The sliding mode control step response with saturation function for: (a) The angular velocities,

(b) Control input

\subsection{PI, PID controllers' results}

Figure 6(a) shows the angular velocities of the top drive and that of the drill bit for a PI controller with $k_{p}=600, T_{I}=0.01 \lambda=0.02$, it was noticed that the two velocities followed the desired set point nominal velocity, without overshoot and without static difference. However, the system was stabilized at $t=$ $250 s$ which is not unacceptable because the torsional vibrations dynamic is faster than that and it can damage the equipment in less time. Figure 6(b) shows the angular velocities of the top drive and that of the drill bit for a PID controller with $k_{p}=-0.1, T_{I}=-10, T_{d}=-0.1, \lambda=2.5$, the obtained performance is almost the same as the one obtained by a PI controller [35], except that the stabilization time was reduced to 200s. These performances prove the effectiveness of the PI controller, it can be seen that the response obtained has no overshoot, compared to [6], we conclude that performance of this controller were significantly improved.

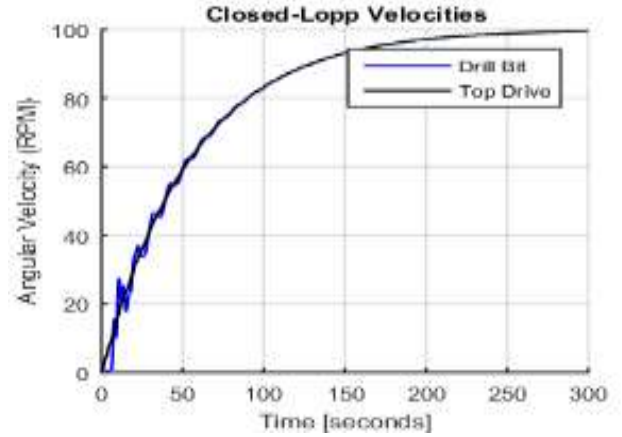

(a)

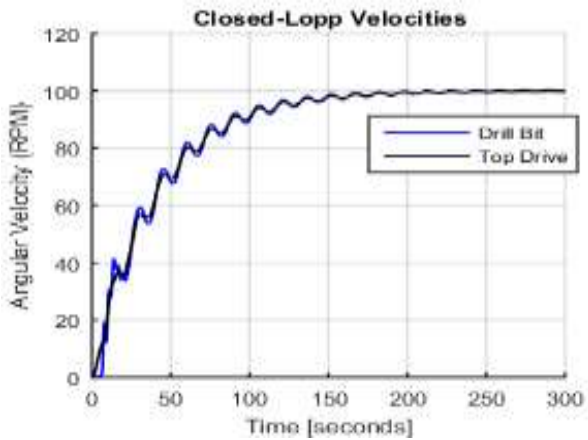

(b)

Figure 6. The step response of rotary drilling system for: (a) PI controller, (b) PID controller 


\subsection{Hybrid controllers' results}

Figure 7(a) shows the angular velocities of the top drive and that of the drill bit for hybrid sliding PI controller with $\lambda=0.1, \mathrm{k}=9.6, \varphi=2, k_{p}=0.2$, and $T_{I}=20$. It was notice that with this controller has a $30 \%$ overshoot while the two velocities were stabilized at $t=40 \mathrm{~s}$. Moreover, Figure 7(b) demonstrated that input controller did not have chattering effects, but the controller was a little oscillating around the nominal velocity of $100 \mathrm{rpm}$, thus, it was concluded that the obtained performance is acceptable.

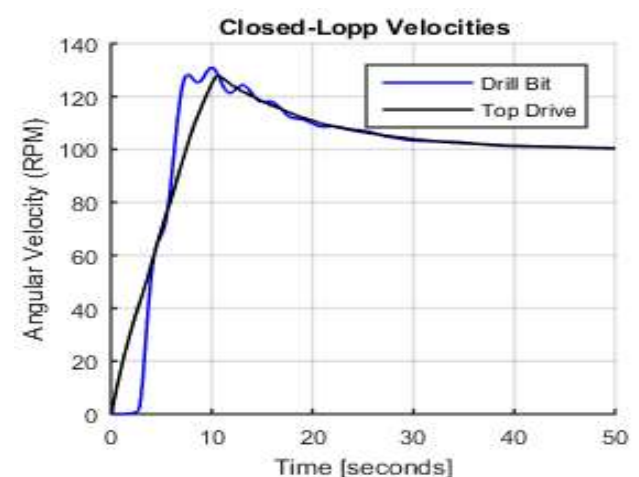

(a)

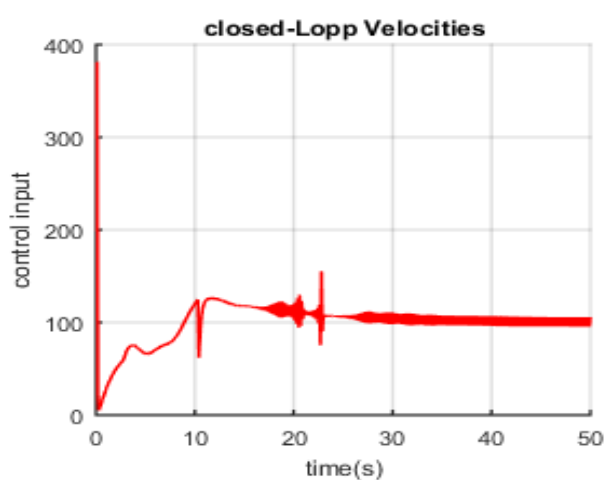

(b)

Figure 7. The step response of hybrid sliding PI controller: (a) Angular velocities, (b) Control input

Figure 8(a) shows the angular velocities of the top drive and that of the drill bit for hybrid sliding PID controller with $\lambda=0.001, \mathrm{k}=9.6, \varphi=2, T_{d}=0.1, k_{p}=0.01$, and $T_{i}=100$, the obtained performances were better than those obtained by hybrid PI controller with shortest stabilization time $t=10 \mathrm{~s}$. The chattering phenomenon has also been eliminated Figure 8(b), these performances prove the effectiveness of the hybrid sliding PID controller, therefore, we can see that the obtained response for a stabilization time of $10 \mathrm{~s}$ with no overshoot. By comparing these characteristics to results in [7], we conclude that the performance of this controller are not just better than the previous controllers in the study but it is even better than controller in [7]. More detailed comparison is given in section seven.

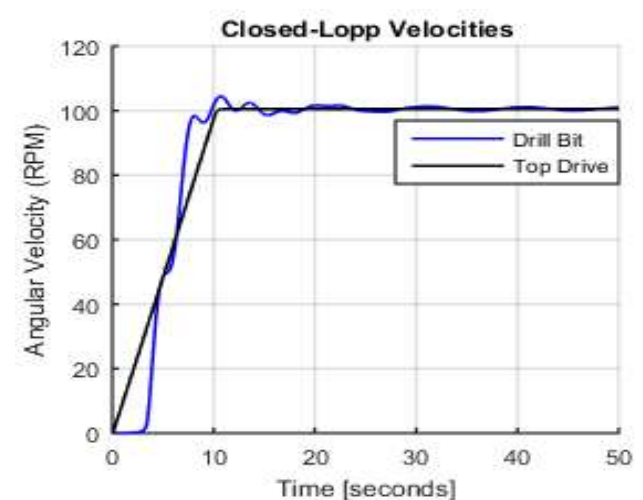

(a)

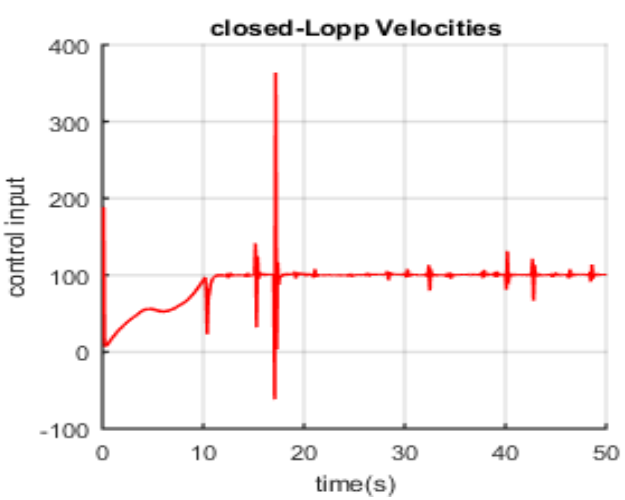

(b)

Figure 8. The step response of hybrid sliding PID controller: a) Angular velocities, b) Control input

\subsection{Robustness results by sliding controller}

Figure 9 demonstrated the robustness of the hybrid controller for parametric variation Figure 9(a) and weight on bit variations Figure 9(b). The response of the system under the parameters $\Delta_{1}=0.7, \Delta_{2}=0.6$, $\Delta_{3}=0.9$, and $\Delta_{4}=0.6$ had showed that controller is robust for such type of status. From the other side, the weight on bit change to 200 has stimulated some oscillations as shown in Figure 9(b), but they are not severe and will not create damage risk to drilling equipment [36]. Therefore, the performance of this system is not 
affected by an increase in the weight on the bit and the parametric change of the sliding mode controller; therefore, we have demonstrated the efficiency and confirmed the validity of the control system based on the results obtained in Matlab R2015 environment.

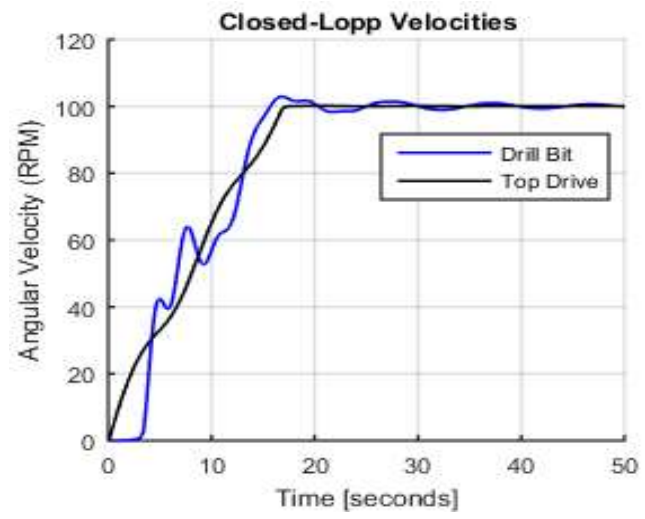

(a)

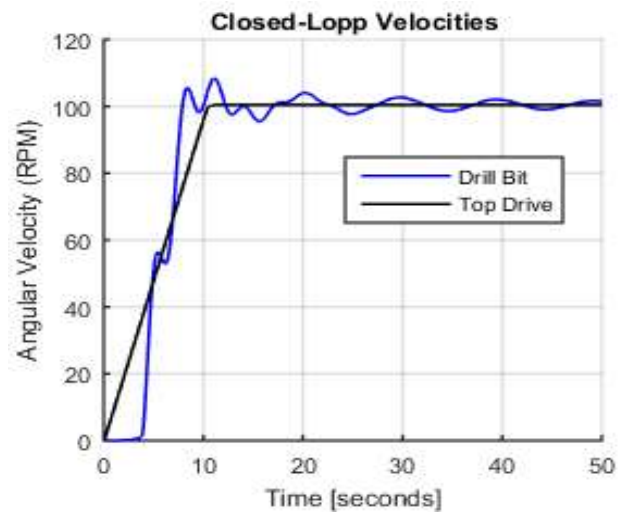

(b)

Figure 9. Robustness evaluation of the hybrid controller with: (a) Parametric variation, (b) Weight on bit variation

\section{COMPARATIVE STUDY}

A comparative study of the controllers' performances is summarized in Table 3, the responses of hybrid PID sliding controller Figure 8(a) are slightly better than those of sliding mode controller Figure 5(a) even they had almost the same performance characteristics Table 3. On the other hand, the responses with PI and PID controllers were not good because of the existence of many oscillations and the long stabilization time which is not practically desirable. Even though the sliding mode had improved their performances, the hybridization had offered the best results in terms of overshoot $(0 \%)$, stabilization time (10s), static difference (0), and oscillations mitigation effectiveness. The other difference is that the input control response for the sliding mode controller was smooth starting from $t=12 \mathrm{~s}$ Figure 5(b). On the contrary, the hybrid sliding PID controller input contained some oscillations, the strongest peak was at $t=17 \mathrm{~s}$ when the angular velocity exceeded $350 \mathrm{rpm}$, and this can generate significant fatigue for the components of the drilling equipment. Despite, the fast time response will prevent the drilling equipment from damages due to the high robustness of the hybrid controller [37, 38].

Table 3. Comparative study between designed controllers' performances

\begin{tabular}{lccc}
\hline Method & Overshoot & $\begin{array}{c}\text { Performance } \\
\text { Stabilization time }\end{array}$ & Static difference \\
\hline Sliding mode & $0 \%$ & $10 \mathrm{~s}$ & 0 \\
PI controller & $0 \%$ & $250 \mathrm{~s}$ & 0 \\
PID controller & $0 \%$ & $200 \mathrm{~s}$ & 0 \\
Hybrid sliding PI controller & $30 \%$ & $40 \mathrm{~s}$ & 0 \\
Hybrid sliding PID controller & $0 \%$ & $10 \mathrm{~s}$ & 0 \\
\hline
\end{tabular}

\section{CONCLUSION}

In this study, a hybrid sliding PID controller was designed to mitigate torsional vibrations in rotary drilling systems so that the dynamic of drill bit remain under desired nominal angular velocity. In addition to that, the chattering phenomenon of sliding controller had also been avoided by the appropriate function choice in the equivalent control law. The hybridization between PI (PID) controllers with the sliding mode control had remarkably improved the performance of the system under the stick-slip vibration in its high frequency mode; the stabilization time was the most important characteristic because its reduction allowed us to suppress the vibrations quickly in order to avoid any damages or fatigues to the drill bit, tool string, and top drive. Furthermore, the comparative study gave us the chance to demonstrate the superiority of sliding 
PID controller over sliding PI controller, and even sliding controller too. Due to the considerable interest in industrial improvements of drilling systems and to control vibration (stick-slip phenomenon), it is suggested to implement the sliding mode controller and hybrid sliding PID controller in the LabVIEW environment (laboratory virtual instrument engineering workbench) in real time, to ensure the reliability and precise synchronization of the speed of our drilling system (top drive and that of the drill). Therefore, small difference between these speeds can be avoided because it is the origin of many failures in the drill. Furthermore, to ensure the proposed controller efficiency in real rotary drilling system, we suggest implementing the developed algorithm in RT-Lab (real time laboratory system) at the beginning, then, in an operating drilling system at the end. Based on the obtained results, it is highly recommendable to consider the proposed hybrid controller for torsional vibrations mitigation in smart industrial rotary drilling system due to its high robustness and its straight forward implementability in the petroleum industry.

\section{ACKNOWLEDGEMENTS}

This research work was sponsored by DGRSDT (Direction Générale de la Recherche Scientifique et du Développement Technologique) Algiers- Algeria.

\section{REFERENCES}

[1] T. Vromen et al., "Mitigation of Torsional Vibrations in Drilling Systems: A Robust Control Approach," IEEE Transactions on Control Systems Technology, vol. 27, no. 1, pp. 249-265, Jan. 2019, doi: 10.1109/TCST.2017.2762645.

[2] T. Jialin et al., "Torsional Vibrations and Nonlinear Dynamic Characteristics of Drill Strings and Stick-Slip Reduction Mechanism," J. Comput. Nonlinear Dynam., vol. 14, no. 8, pp. 081007 (11 pages), Aug. 2019, doi: 10.1115/1.4043564.

[3] S. Adly and D. Goeleven, "A nonsmooth approach for the modelling of a mechanical rotary drilling system with friction," Evolution Equations and Control Theory, AIMS, In press, X, 2020, doi: 10.3934/eect.2020042.

[4] I. Kessai, S. Benammar, M. Z. Doghmane and K. F. Tee, "Drill Bit Deformations in Rotary Drilling Systems under Large-Amplitude Stick-Slip Vibrations," Appl. Sci, vol. 10, no. 18, pp. 6523, 2020, doi: 10.3390/app10186523.

[5] F. K. Ullah and C. Bohn, "Dynamic Surface Control for the Reduction of Torsional Vibrations in a Scaled Experimental Drillstring Setup," 2018 UKACC 12th International Conference on Control (CONTROL), Sheffield, 2018, pp. 199-204, doi: 10.1109/CONTROL.2018.8516736.

[6] E. Navarro-L'opez and E. Lic'eaga-Castro, "Non-desired transitions and sliding mode control of a multi-DOF mechanical system with stick-slip oscillations," Chaos, Solitons Fractals, vol. 41, no. 4, pp. 2035-2044, 2009, doi: 10.1016/j.chaos.2008.08.008.

[7] M. Z. Doghmane, A. Bacetti and M. Kidouche, "Stick-slip Vibrations Control Strategy Design for Smart Rotary Drilling System," accepted for presentation and publication in Proceeding of the Fourth Conference on Artificial Intelligence in Renewable Systems, Tipasa, Algeria, 22-24 November, 2020. doi: 10.1007/978-3-030-63846-7_20.

[8] Y. Liu, "Suppressing stick-slip oscillations in underactuated multibody drill-strings with parametric uncertainties using sliding-mode control," The Institution of Engineering and Technology, vol. 9, no.1, pp.91-102, Jan. 2015, doi: 10.1049/iet-cta.2014.0329.

[9] V. Zahiri, M. Kapitaniak and M. Wiercigroch, "Suppression of drill-string stick-slip vibration by sliding mode control: Numerical and experimental studies," Journal of Applied Mathematics, vol. 29, pp. 805-825, 2018, doi: 10.1017/S0956792518000232.

[10] C. Mendil, M. Kidouche and M.Z. Doghmane, "Modeling of Hydrocarbons Rotary Drilling Systems under Torsional Vibrations: A Survey," accepted for presentation and publication in Proceeding of the Fourth Conference on Artificial Intelligence in Renewable Systems, Tipasa, ALGERIA, 22-24 November, 2020. doi: 10.1007/978-3-030-63846-7_24.

[11] R. Riane, M. Kidouche, M. Z. Doghmane and R. Illoul, "Modeling of Torsional Vibrations Dynamic in Drill-String by Using PI-Observer," In Proc. Of the Fourth International Conference on Electrical Engineering and Control Applications ICEECA'19- Recent Advances in Electrical Engineering and Control Applications Constantine, Algeria, 2019, doi: 10.1007/978-981-15-6403-1_12.

[12] K. Oulidi Omali et al., "Actuator fault detection and isolation for robot manipulator using higher order sliding mode observers," Indonesian Journal of Electrical Engineering and Computer Science (IJEECS), vol. 17, no. 3, pp. 1150 1156, Mar. 2020. doi: 10.11591/ijeecs.v17i3.pp1150-1156.

[13] Y. A Mohammed Alkaragoolee, "Hybrid Modelling and Optimisation of Oil Well Drillstrings," PhD Thesis, University of Bradford, 2018. http://hdl.handle.net/10454/16859.

[14] C. Mendil, M. Kidouche, M.Z. Doghmane, "A study of the Parametric Variations Influences on Stick-Slip Vibrations in Smart Rotary Drilling Systems," accepted for presentation and publication in Proceeding of the Fourth Conference on Artificial Intelligence in Renewable Systems, Tipasa, ALGERIA, 22-24 November, 2020. doi: 10.1007/978-3-030-63846-7_67. 
[15] R. Riane, M. Kidouche, R. Illoul and M. Z. Doghmane, "Unknown Resistive Torque Estimation of a Rotary Drilling System Based on Kalman Filter," IETE Journal of Research, published online: 27 Feb 2020, doi: 10.1080/03772063.2020.1724834.

[16] F. Mehedi et al., "SMC based DTC-SVM control of five-phase permanent magnet synchronous motor drive," Indonesian Journal of Electrical Engineering and Computer Science (IJEECS), vol. 20, no. 1, pp. 100-108, 2020, doi: 10.11591/ijeecs.v20.i1.pp100-108.

[17] B. Saldivar et al., "An overview on the modeling of oilwell drilling vibrations," IFAC Proceedings Volumes, vol. 47, no. 3, pp. 5169-5174, 2014, doi: 10.3182/20140824-6-ZA-1003.00478.

[18] Y. Xiao, C. Hurich and S. D. Butt, "Assessment of rock-bit interaction and drilling performance using elastic waves propagated by the drilling system," International Journal of Rock Mechanics and Minning Sciences, vol. 105, pp. 11-21, 2018, doi: 10.1016/j.ijrmms.2018.02.006.

[19] A. Marquez and C. Teodoriu, "A Novel Drillstring Dynamics Experimental Setup to Be Integrated into Hardware in the Loop Capable Drilling Simulators," in Proceeding series, International Conference on Offshore Mechanics and Arctic Engineering, Paper No: OMAE2017-62395, V008T11A026, 2017, p, 7, doi: 10.1115/OMAE201762395.

[20] T. L. Nguyen and H. T. Vu, "Contribution to the adaptive observer synthesis with unknown input of rotary drilling system: Simulation under LabView Environment," Bulletin of Electrical Engineering and Informatics (BEEI), vol. 9, no. 5, pp. 1844-1853, October 2020, doi: 10.11591/eei.v9i5.2143.

[21] M. Krøtøy and J. T. Myrvold, "Stick-Slip Prevention of Drill Strings Using Nonlinear Model Reduction and Nonlinear Model Predictive Control," Master thesis, Norwegian University of Science and Technology Department of Engineering Cybernetics, 2010.

[22] M. Kidouche and A. Charef, "A constructive methodology of Lyapunov function of composite systems with nonlinear interconnected term", Internal journal of Robotics and Automation, vol. 21, no. 1, pp. 19-24, 2006, doi: 10.2316/Journal.206.2006.1.206-2814.

[23] A. Aibeche and M. Kidouche, "Sensor Fault Detection, Localization, and System Reconfiguration with a Sliding Mode Observer and Adaptive Threshold of PMSM," Journal of Power Electronics, vol. 16, no. 3, pp. 1012-1024, May 2016, doi: 10.6113/JPE.2016.16.3.1012.

[24] N. Mamat et al., "Performance Comparison of Controllers for Suppressing the Structural Building Vibration," Indonesian Journal of Electrical Engineering and Computer Science (IJEECS), vol. 10, no. 2, pp. 537-544, May 2018, doi: 10.11591/IJEECS.V10.I2.PP537-544.

[25] M.Manceur, "Commande robuste des systemes non lineaires complexes," Doctoral thesi in Automation, STIC research center, l'Univérsite de Reims Champagne-Ardenne, 2012.

[26] M. Kidouche and R. Riane, "On the design of proportional integral observer for a rotary drilling system," 8th CHAOS Conference Proceedings, Henri Poincaré Institute, Paris France, 2015.

[27] R.Mohamed, M. Helaimi, et al.,"Frequency control of microgrid system based renewable generation using fractional PID controller," Indonesian Journal of Electrical Engineering and Computer Science (IJEECS), vol. 19, no. 2, 2020, pp. 745-755. doi: 10.11591/ijeecs.v19.i2.pp745-755.

[28] M. Z. Doghmane, "Optimal decentralized control design with overlapping structure," Magister Thesis, Department of Automation, FHC, University M'hamed Bougara of Boumerdes, Algeria 2011.

[29] M.H. Gebrehiwot, "Speed control of PM brushless DC motor using sensorless hybrid controller," International Journal of Applied Power Engineering (IJAPE), vol. 10,no. 2, June 2021.

[30] C. Mendil, M. Kidouche and M. Z. Doghmane, "Automatic Control of Heat Exchanger in a Nuclear Power Station: The Classical and the Fuzzy Methods," In IEEE International Conference on Advanced Electrical Engineering (ICAEE), Algiers-Algeria, 2019, doi: 10.1109/ICAEE47123.2019.9014661.

[31] Z.Massaq, A.Abounada and M.Ramzi, "Robust non-linear control of a hybrid water pumping system based on induction motor," International Journal of Power Electronics and Drive Systems (IJPEDS), vol. 11, no. 4, 2020, doi: 10.11591/ijpeds.v11.i4.pp1995-2006.

[32] N.M. Ameen and A.T.Humod, "Robust nonlinear PD controller for ship steering autopilot system based on particle swarm optimization technique, "IAES International Journal of Artificial Intelligence (IJ-AI), vol. 9, no. 4, 2020, doi: 10.11591/ijai.v9.i4.pp662-669.

[33] S. Riache, M. kidouche and A. Rezoug, "Adaptive robust nonsingular terminal sliding mode design controller for quadrotor aerial manipulator," TELKOMNIKA (Telecommunication, Computing, Electronics and Control), vol.17, no. 3, pp. 1501-1512, Jun. 2019, doi: 10.12928/telkomnika.v17i3.10470.

[34] P.Padmalatha and S.Thomas, "Discrete time reaching law based variable structure control for fast reaching with reduced chattering," IAES International Journal of Robotics and Automation (IJRA), vol.9, no.1, March 2020, doi: 10.11591/ijra.v9i1.pp51-61.

[35] M. Z. Doghmane and M. Kidouche, "Decentralized controller Robustness improvement using longitudinal overlapping decomposition- Application to web winding system," Elektronika ir Elektronika, vol. 24, no. 5, pp. 1018, 2018, doi: 10.5755/j01.eie.24.5.21837.

[36] M. Z. Doghmane et al., "A new decomposition strategy approach applied for a multi-stage printing system control optimization," In $4^{\text {th }}$ International Conference on Electrical Engineering (ICEE), Boumerdes, Algeria, 2015, doi: 10.1109/INTEE.2015.7416751.

[37] A.Mousmi, A. Abbou et al., "Real time implementation of a super twisting control of a BLDC motor," International Journal of Electrical and Computer Engineering (IJECE), vol. 9, no. 4, August 2019, doi: 10.11591/ijece.v9i4.pp3032-3040. 
[38] A.Idir, A. Ahriche, K. Khettab, Y. Bensafia and M. Kidouche, "Real time simulation of sensorless control based on back-EMF of PMSM on RT-Lab/ARTEMIS real-time digital simulator," International Journal of Advances in Applied Sciences (IJAAS), vol. 8, no. 4, December 2019, doi: 10.11591/ijaas. v8.i4.pp269-278.

\section{BIOGRAPHIES OF AUTHORS}

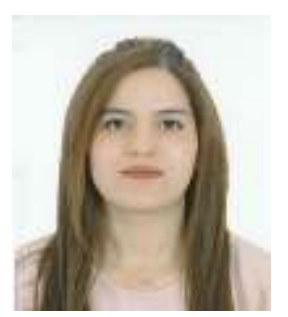

Chafiaa Mendil was born in 1993 in Sidi Aich, Bejaia, Algeria. She holds a Master's degree in Automation from Faculty of Hydrocarbons and Chemistry, University M'hamed Boughara of Boumerdes, Algeria. She is now a member in research group of "Control of complex dynamical systems" at Applied Automatic Control Laboratory (LAA), Faculty of Hydrocarbons and Chemistry, M'hamed Bougara University of Boumerdes where she prepares her PhD Thesis. She is currently interested in research development of nonlinear control in Petroleum industry.

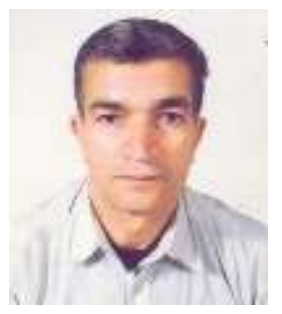

Kidouche Madjid was born in Bordj-Menaiel, Algeria. He received Engineering, Master of Sciences, and Ph.D degrees all in control theory. He joined M'hamed Bougara University of Boumerdes, Algeria in 1990 where he is a full Professor in the department of automation and electrification of industrial process. He is a research group head on "Control of complex dynamical systems" at Applied Automatic Control Laboratory. He has been actively involved in several research projects in the fields of control and power system analysis. He is the author and co-author of numerous research publications in international conferences and journals. His research interests include modeling and control of dynamic non linear systems, stability of large scale systems, fuzzy and sliding mode control.

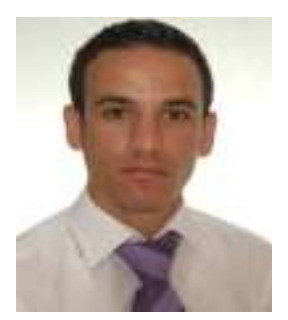

Doghmane Mohamed Zinelabidine was born in Bousàada, Algeria. He holds a Ph.D degree in Electrical engineering From Faculty of Hydrocarbons and Chemistry, university M'hamed Bougara of Boumerdes, Magister degree in Geophysics from IAP, Magister degree in Applied Automatic from department of Automation and electrification of industrial process, Faculty of Hydrocarbons and Chemistry, University of Boumerdes. An engineering degree from the National institute of electrical and electronics engineering (Ex-INELEC) Boumerdes, Algeria. Now, he is working as Petrophysicist in Exploration Operations Direction of SONATRACH (Algeria), and he is member in research laboratory, university of Boumerdes. His current research interest is reservoir evaluation and optimization of control design for complex systems in petroleum engineering. 